\section{Chemical Composition of the Martian Crust: Geophysical Constraints from the InSight Mission}

\author{
SCOTT M. MCLENNAN ${ }^{1}$, AMIR KHAN ${ }^{2}$, BRIGITTE \\ KNAPMEYER-ENDRUN ${ }^{3}$, CHLOÉ MICHAUT ${ }^{4}$, MARK P. \\ PANNING $^{5}$, A.-C. PLESA ${ }^{6}$, HENRI SAMUEL ${ }^{7}$, SUZANNE E. \\ SMREKAR $^{5}$ AND MARK A. WIECZOREK ${ }^{7}$ \\ ${ }^{1}$ Stony Brook University \\ ${ }^{2}$ Institute of Geophysics, ETH Zurich \\ ${ }^{3}$ University of Cologne \\ ${ }^{4}$ Ecole Normale Supérieure de Lyon \\ ${ }^{5}$ Jet Propulsion Laboratory, California Institute of Technology \\ ${ }^{6}$ German Aerospace Center \\ ${ }^{7} \mathrm{CNRS}$ \\ Presenting Author: scott.mclennan@stonybrook.edu
}

Models for the chemical composition of Martian crust rely on near-surface measurements, including orbital gamma-ray (GRS) geochemical mapping, in situ analyses of regoliths and chemical deconvolution of mineral distributions derived from orbital spectroscopy. A fundamental outstanding question is whether or not such compositional models apply to the full thickness of the crust or whether there may be significant vertical variations in composition. New seismic data from the InSight Lander [1,2], coupled with crustal and thermal modeling based on InSight data $[2,3]$ provide important new constraints on the nature and composition of the Martian crust. Although uncertainty remains in the exact Moho depth, all models indicate a seismically layered crust $<68 \mathrm{~km}$ thick (possibly as thin as $\sim 28 \mathrm{~km}$ ) and with a density $\leq 3100 \mathrm{~kg} / \mathrm{m}^{3}$ (possibly as low as $\sim 2550 \mathrm{~kg} / \mathrm{m}^{3}$ ), lower than expected for known basaltic surface materials [2]. Thermal modeling consistent with this range of values and that restricts mantle melting to local occurrences beneath Tharsis indicates well in excess of half the planet's radiogenic heat production resides within the crust [3]. These constraints suggest that current crustal compositional models may underestimate HPE (and other incompatible element) concentrations and that the crust underlying the near-surface is less mafic and less dense on average. Geochemical layering of the terrestrial crust results from intracrustal differentiation generating felsic rocks in upper continental crust and MORB in upper oceanic crust, both resulting in upward enrichments of incompatible elements. Thus, for intracrustal differentiation to explain low heat production in Martian uppermost crust, it would need to be fundamentally different in order to result in downward HPE enrichments. Alternatively, and consistent with GRS data [4], younger resurfacing by incompatible element-depleted basalts, similar to many Martian meteorites, may "dilute" the heat production in the uppermost crust that is sampled by geochemical/mineralogical measurements interrogating only the near-surface, leaving the bulk of the crust somewhat more felsic and less dense than currently thought.

[1] M.P. Panning et al. (2021) 52nd LPSC, Abst.1590; [2] M.A. Wieczorek et al. (2021) 52nd LPSC, Abst.1412; [3] C. 